\title{
Asbestos related malignancy and the Cairns hypothesis
}

\section{The hypothesis}

Natural selection between individual organisms, leading to survival of the fittest, may be beneficial for the species. Growth and survival within the tissues of each organism must, however, be coordinated; competition for survival between cells within one organism is the pathway to a malignancy. During the life of the average person, some $10^{16}$ cell divisions take place. It is accepted that most mutations arise during DNA replication with a spontaneous mutation rate of the order of $10^{-6}$ per gene per cell division. It seems probable that some of the vast number of mutations occurring during a lifetime might release the mutated cell from some of the normal restraints on cell multiplication. This would confer a survival advantage that in time could lead to tumour formation. Because of this a protective mechanism is likely to have evolved which would reduce the probability of such "fitter" cells arising.

After giving this outline, Cairns ${ }^{1}$ suggested three possible features of the protective mechanism: firstly, the preservation of the stem cell-"the immortal cell"-with further cell division taking place in the daughter cells that are destined to be discarded ${ }^{2}$; secondly, within stem cells, the preservation of the original DNA strand- " "the immortal strand"-after cell division, whereas the newly formed strand is passed to the daughter cell to be discarded; thirdly, the existence of a spatial arrangement that would restrict competition. Since the original paper appeared there has been increasing support for the hypothesis and, independently, for the stem cell model of neoplasia, ${ }^{3}$ and chronic cell proliferation that would disrupt the protective mechanism, predisposing to malignancy. ${ }^{5}$

Asbestos appears to pose the opposite problem. Exposure to airborne asbestos leads in some circumstances to lung cancer and (with the possible exception of chrysotile) mesothelioma. But it is not a mutagen, and attempts to establish a mechanism whereby it can directly produce malignant transformation in bronchial epithelium or mesothelium have either failed completely or have required unrealistic in vitro conditions. ${ }^{67}$ Particularly, most of the ingenious methods proposed do not meet the conditions of dose, durability, and dimension found to be prerequisites for tumour development in vivo. Dimension is a particular difficulty. Asbestos per se is not carcinogenic, but only asbestos exceeding a certain length. The evidence in experimental animals, ${ }^{8-11}$ with some support from human epidemiology, ${ }^{12-13}$ is compelling that fibres shorter than $5 \mu$ are neither fibrogenic nor carcinogenic.

\section{The pathogenesis of asbestosis}

A consensus exists that asbestosis (diffuse interstitial pulmonary fibrosis, DIPF) results from the effect of mediators released by lung macrophages after incomplete phagocytosis. ${ }^{6}$ Alveolar macrophages produce many mediators, including lysosomal enzymes, active oxygen metabolites, ${ }^{14}{ }^{15}$ and growth factors. ${ }^{16}$ When released in sufficiently large quantities, some mediators may cause damage to the epithelium. Others may trigger fibroblast and epithelial proliferation. ${ }^{17}$ But whereas inflammatory changes in the lung produced by the interaction of macrophages and short fibres have been shown to be transient, ${ }^{910}$ fibres too long to be completely ingested may produce lifelong effects. The DIPF and uncontrolled proliferation of epithelium with loss of alveolar architecture ${ }^{18}$ arise directly from this chronic release of mediators. Asbestos is not fatally toxic to macrophages, ${ }^{19}$ and fibres incompletely ingested by one macrophage may be taken up by another when the first one dies, thus continuing the cycle.

The effects of macrophage mediators on the surrounding tissues depend on the quantity released. ${ }^{20}$ Macrophages are modulating agents capable of producing fibrinolysis and fibrogenesis, ${ }^{21}$ and fibrogenesis will only predominate when the fibre burden is excessive. A threshold effect is therefore implied in this fibrinolysis-fibrinogenesis balance, and in man a threshold for cumulative exposure of 25 fibre/ $\mathrm{ml}$ years (the product of duration and intensity) below which clinical asbestosis will not appear has been generally accepted. ${ }^{22} 23$ 


\section{Lung cancer and asbestosis}

Excess production of fibroblast growth factors by macrophages is accompanied by excess production of epithelial growth factors. The resultant uncontrolled proliferation leading to loss of alveolar structure, metaplasia and adenosis development, and ultimately neoplasia, has been traced in detail. ${ }^{18}$ This accords with disruption of the protective mechanism suggested by Cairns. It also economises in hypotheses, postulating only one single pathological effect of asbestos-namely, the release of macrophage mediators following incomplete phagocytosis. ${ }^{24}$

Powerful evidence that no additional carcinogenic action specific to asbestos is needed comes from studies of DIPF from other causes. In cryptogenic fibrosing alveolitis the histological picture may be indistinguishable from asbestosis apart from the absence of excess asbestos bodies or fibres, and patients suffering from this disease, or from DIPF secondary to other systemic diseases, show a greatly increased incidence of lung cancer. ${ }^{25}$

If asbestosis and asbestos related lung cancer are both consequences of excess growth factors, fibrosis and malignancy should run in parallel, although the threshold level of exposure for each need not be the same. Evidence for this parallel relation has been recently reviewed, ${ }^{26}{ }^{27}$ and since then two studies specifically designed to test the hypothesis have been reported; both found positive evidence that lung cancer risk was only increased in the presence of radiological ${ }^{28}$ or pathological ${ }^{29}$ evidence of asbestosis.

The relative risk for lung cancer in subjects with asbestosis who also smoke is more than additive. This is predictable from the Cairns hypothesis. If the carcinogens in cigarette smoke have caused DNA damage to large numbers of lung epithelial cells, chronic proliferation of some of these cells will more readily result in the expression of malignancy than from both mechanisms independently. Asbestos is then acting as a classical promoter on already initiated cells. "Mitogenesis increases mutagenesis." 30

\section{Asbestos and mesothelioma.}

Although some relation between asbestosis and lung cancer is increasingly accepted, its essential nature has been doubted because exposure to asbestos may cause mesothelioma without asbestosis. Evidence now indicates, however, that mesotheliomas may arise in a pathological setting similar to that giving rise to asbestos related lung cancer.

Even when directly implanted, fibres must be longer than $5 \mu$ to produce mesotheliomas. Other evidence confirming an intermediate mechanism rather than direct carcinogenicity includes inflammatory change preceding mesothelioma development, the existence of a threshold, dose response lengthening of the latent period, and the by now well established finding that a wide range of non-asbestos fibres of comparable dimensions will also produce mesotheliomas after implantation.

\section{INFLAMMATORY CHANGE}

Stanton et $\mathrm{l}^{31}$ in 1981 suggested the importance of hypotheses in which the progenitor of the cancer cell is not directly affected by the fibre; they noted particularly the abundant collagen in the preneoplastic scars. Suzuki and Koyama ${ }^{32}$ found fibrosis as a precondition of mesothelioma induction by implanted minerals. It has been shown (JMG Davis, personal communication) that if amosite is injected intraperitoneally in several doses (a procedure which increases the inflammatory response) more mesotheliomas result than if the same total dose is given as a single injection. In man the main group of non-fibre related mesotheliomas thought to be associated with identified causes such as radiation, tuberculosis, or empyema, are all associated with chronic inflammatory change. ${ }^{33}$

The deduction from these findings seems to be that the presence of phagocytic cells is an integral part of the process, and that the carcinogenic action of asbestos cannot result from a direct effect on the genome. The histological changes that occur after implantation of fibres in experimental animals up to the development of mesothelial tumours have recently been described in detail. ${ }^{34-36}$ The descriptions provide strong evidence for the sequence of inflammation, localised destruction of tissue structure, participation of subserosal cells (almost certainly mesothelial stem cells), and chronic proliferation leading to invasive development.

\section{EVIDENCE OF A THRESHOLD}

Epidemiological evidence supports the existence of an exposure level to fibre below which mesotheliomas are not induced. A review of evidence from animals and man $^{37}$ suggests a threshold in the region of five fibres/ml-years for exposure to amphibole asbestos. This is nearly an order of magnitude lower than that suggested for asbestosis and lung cancer, due perhaps to the lower resistance to malignant transformation of mesothelium, which has not evolved to withstand chronic insult to the same extent as epithelium. In animals threshold levels can be deduced from both inhalation and implantation experiments.

Despite the greatly increased use of asbestos since 1940 , trends in mortality from mesothelioma from several countries show no evidence of increase due to environmental exposure. ${ }^{38}$ Examinations of lung burdens of two groups exposed to tremolite have found higher fibre concentrations in the hazardous size range without detectable excess of mesotheliomas. ${ }^{39} 40$ 


\section{LENGTHENING OF THE LATENT PERIOD}

Perhaps the most crucial experimental evidence concerns the latent period. Four research groups have independently reported that when the dose of injected fibre is reduced, not only is the number of mesotheliomas reduced but also the average latent period before malignant transformation takes place is lengthened. ${ }^{3438412}$ Such a situation is incompatible with any role for asbestos as an initiator, but is what would be predicted by the Cairns hypothesis, as the time scale and intensity of chronic proliferation would, through macrophage mediation, be directly related to dose. This is perhaps why chrysotile is rarely associated with mesothelioma in man although it is known to reach the pleura; its tendency to fragment, and thereby to permit complete ingestion by macrophages, would prevent it from causing sufficient chronic proliferation.

\section{Conclusion}

The evidence suggests that asbestosis, lung cancer, and mesothelioma result from the single pathological effect of long fibres, which cause release of macrophage mediators after incomplete ingestion. The malignant changes do not result from direct genotoxic action. The probability of their development after exposure to asbestos (or other respirable durable fibre) of appropriate dimensions is subject to threshold and dose response effects.

Both the histology and the course of development of mesothelioma in experimental animals suggest that neoplastic change originates in stem cells after chronic proliferation and destruction of the normal tissue architecture. The last two features are also identifiable in the development of lung cancer. Taken with the failure to identify a chemical cause, the development of mesothelioma after implantation of a wide range of non-asbestos durable fibres, and the excess lung cancer that occurs with DIPF unrelated to asbestos exposure, the evidence is consistent with the attribution of asbestos related malignancy to a disruption of the natural mechanism for protection from harmful mutations arising during cell division as suggested by Cairns. ${ }^{1}$

Department of Occupational Medicine,

KEVIN BROWNE

National Heart and Lung Institute,

Emmanuel Kaye Building,

London SW3 6LR

1 Cairns J. Mutation selection and the natural history of cancer. Nature 1975;255:197-200.

2 Kay HEM. How many cell generations? Lancet 1965;ii:418-9.

3 Editorial. Stem cells in neoplasia. Lancet 1989;i:701-2.

4 Albanes $D$, Winick $M$. Are cell number and cell proliferation risk factors for cancer? J Natl Cancer Inst 1988;80:772-5.

5 Cohen S, Elwein L. Cell proliferation in carcinogenesis. Science 1990;249:1007-11.

6 Mossman BT, Bignon J, Corn M, Seaton A, Gee JBL. Asbestos: scientific developments and implications for public policy.
Science 1990;247:294-301.

7 Barrett JC, Lamb PW, Wiseman RW. Multiple mechanisms for the carcinogenic effects of asbestos and other mineral fibres. Environ Health Perspect 1989;81:81-9.

8 Davis JMG. The pathogenicity of long versus short fibre samples of amosite. $\mathrm{Br} J$ Exp Pathol 1986;67:415-30.

9 Platek SF, Groth DE, Ulrich CE, et al. Chronic inhalation of short asbestos fibres. Fund Appl Toxicol 1985;5:327-40.

10 Adamson I, Bowden DH. Response of mouse lung to crocidolite. Minimal fibrotic reaction to short fibres. J Pathol 1987; 152:99-107.

11 Wagner JC. Significance of the fibre size of erionite. In: Proceedings of the 7 th international pneumoconioses conference, 1988, Pittsburgh (in press).

12 Friedrichs $\mathrm{KH}$, Otto $\mathrm{H}$. Fibres in human lung dust samples: a scanning electron microscope study. Am Ind Hyg Assoc J $1981 ; 42: 150-6$.

13 McDonald JC, Armstrong B, Case B, et al. Mesothelioma and asbestos fibre type. Cancer 1989;63:1544-7.

14 Case BW, Michael PC, Padilla M, Kleinerman J. Asbestos effects on superoxide production. Environ Res 1986;39: 299-306.

15 Hansen K, Mossman BT. Generation of superoxide from alveolar macrophages exposed to asbestiform and non-fibrous particles. Cancer Res 1987;47:1681-6.

16 Lemaire I, Beaudouin H, Masse S, Grondin C. Alveolar macrophage stimulation of lung fibroblast growth in asbestosinduced pulmonary fibrosis. Am J Pathol 1986;122:205-11.

17 Brody AR. Pulmonary cell interactions with asbestos fibres. Chest 1986;89:155S-9S.

18 Davis JMG, Bolton R, Brown D, Tully HE. Experimental lesions in rats corresponding to advanced human asbestosis. Exp Mol Pathol 1986;44:207-21.

19 Miller K, Webster I, Handfield RM, Skikne MI. Ultra-structure of the lung in the rat following exposure to crocidolite and quartz. J Partic 1978;124:39-44.

20 Begin R, Masse S, Rola-Plezczynski M, Boctov M, Drapeau G. Asbestos exposure dose-bronchoalveolar milieu response in asbestos workers and the sheep model. Drug Chem Toxicol 1987;10:87-103.

21 Brain JD. Lung macrophages: how many kinds are there? What do they do? Am Rev Respir Dis 1988;137:507-9.

22 Ontario Royal Commission on matters of health and safety arising from the use of asbestos in Ontario. Toronto: Ontario Ministry of the Attorney General, 1984.

23 Doll R, Peto J. Effects on health of exposure to asbestos. London: HMSO, 1985.

24 Kuschner $M$. The effects of MMMF on animal systems: some reflections on their pathogenesis. Ann Occup Hyg 1987;31: 791-7.

25 Turner-Warwick M, Lebowitz M, Burrows B, Johnson A. Cryptogenic fibrosing alveolitis and lung cancer. Thorax 1980 ; 35:496-9.

26 Browne $\mathrm{K}$. Is asbestos or asbestosis the cause of the increased risk of lung cancer in asbestos workers? $\mathrm{Br} J$ Ind Med 1986; 43:145-9.

27 Browne K. A threshold for asbestos-related lung cancer. Br J Ind Med 1986;43:556-8.

28 Hughes JM, Weill $\mathrm{H}$. Pulmonary fibrosis as a determinant of asbestos-induced lung cancer. In: Proceedings of the 7 th international pneumoconioses conference, 1988. Pittsburgh (in press).

29 Sluis-Cremer GK, Bezuidenhart BN. Relation between asbestosis and bronchial cancer in amphibole asbestos miners. $\mathrm{Br} J$ Ind Med 1989;46:537-40.

30 Ames BN, Gold LS. Too many rodent carcinogens:mitogenesis increases mutagenesis Science 1990;249:970-1.

31 Stanton MF, Layard M, Tegeris A. Relation of particle dimension to carcinogenicity in amphibole asbestoses and other fibrous minerals. $J$ Natl Cancer Inst 1981;65:967-75.

32 Suzuki Y, Kohyama N. Malignant mesothelioma induced by asbestos and zeolite in the mouse peritoneal cavity. Environ Res 1984;35:277-92.

33 Pelnar PV. Further evidence of non-asbestos-related mesothelioma. Scand J Work Environ Health 1988;14:141-4.

34 Hill RJ, Edwards RE, Carthew P. Early changes in the pleural mesothelium following intrapleural inoculation of the mineral fibre erionite and the subsequent development of mesotheliomas. J Exp Pathol 1990;71:105-18.

35 Friemann J, Brinkmann O, Pott F, Muller K. Disturbance of peritoneal differentiation due to asbestos and asbestos substitutes. Verh Disch Ges Pathol 1988;72:312-6.

36 Friemann J, Muller K, Pott F. Mesothelial proliferation due to 
asbestos and man-made fibres. Pathol Res Pract 1990;186: 117-23.

37 Ilgren ED, Browne K. Asbestos-related mesothelioma: evidence for a threshold from human and animal exposure data. Regul Toxicol Pharmacol 1990 (in press).

38 Davis JMG, McDonald JC. Low level exposure to asbestos: is there a cancer risk? $\mathrm{Br} J$ Ind Med 1988;45:505-8.

39 Churg A. Lung asbestos content in long-term residents of a chrysotile mining town. Am Rev Respir Dis 1986;134:125-7.

40 Sebastien P, McDonald JC, McDonald AD, Case B, Harley R. Respiratory cancer in chrysotile textile and mining industries: exposure inferences from lung analysis. $\bar{B} r \bar{j}$ Ind Med 1989;46:180-7.

41 Brand KG. Fibrotic scar cancer in the light of foreign body tumorigenesis. In: Goldsmith DF, Winn DM, Shy CM, eds. Silica, silicosis, and cancer. Controversy in occupational medicine. New York: Praeger, 1986.

42 Pott F, Roller M, Ziem U, et al. Carcinogenicity studies on natural and man-made fibres with the intraperitoneal test in rats. In: Bignon J, Peto J, Saracci R, eds. Non-occupational exposure to mineral fibres. Lyon: IARC scientific pubs 1989; 90:277-90.

\section{Vancouver style}

All manuscripts submitted to the $\mathrm{Br} J$ Ind $\mathrm{Med}$ should conform to the uniform requirements for manuscripts submitted to biomedical journals (known as the Vancouver style)

The $\mathrm{Br} J$ Ind Med, together with many other international biomedical journals, has agreed to accept articles prepared in accordance with the Vancouver style. The style (described in full in $\mathrm{Br}$ Med J, 24 February 1979, p 532) is intended to standardise requirements for authors.

References should be numbered consecutively in the order in which they are first mentioned in the text by Arabic numerals above the line on each occasion the reference is cited (Manson ${ }^{1}$ confirmed other reports ${ }^{2-5} \ldots$ ). In future references to papers submitted to the $\mathrm{Br} J$ Ind Med should include: the names of all authors if there are six or less or, if there are more, the first three followed by et al; the title of journal articles or book chapters; the titles of journals abbreviated according to the style of Index Medicus; and the first and final page numbers of the article or chapter.

Examples of common forms of references are:

1 International Steering Committee of Medical Editors. Uniform requirements for manuscripts submitted to biomedical journals. Br Med J 1979;1:532-5.

2 Soter NA, Wasserman SI, Austen KF. Cold urticaria: release into the circulation of histamine and eosino-phil chemotactic factor of anaphylaxis during cold challenge. $N$ Engl $J$ Med 1976;294:687-90.

3 Weinstein L, Swartz MN. Pathogenic properties of invading micro-organisms. In: Sodeman WA Jr, Sodeman WA, eds. Pathologic physiology: mechanisms of disease. Philadelphia: W B Saunders, 1974:457-72. 